\title{
Temperature-Dependent Development of the Predator, Scolothrips sexmaculatus (Pergande) (Thysanoptera:Thripidae)
}

\author{
Marwa Salahi $^{1 *}$, Abedlnabi Basheer ${ }^{2}$ and Louai Asslan² \\ ${ }^{1}$ Department of Plant Protection, General commission for scientific agriculture research, Damascus, Syria. \\ ${ }^{2}$ Department of Plant Protection, Faculty of Agriculture, Damascus University, Damascus, Syria \\ * Corresponding author: e-mail: marwaalsalahi@yahoo.com
}

\begin{abstract}
The temperature is an important factor that affects the efficacy of biological control agents. Effect of the temperature on life table, parameters of Scolothrips sexmaculatus (Pergande) (Thysanoptera: Thripidae), the predator of the two-spotted spider mite Tetranychus urticae Koch (Acari: Tetranychidae) was studied under laboratory conditions at three constant temperatures $(20,25$ and $30^{\circ} \mathrm{C}$ ). These experiments were conducted at the General Commission for Scientific Agricultural Research (GCSAR), Damascus countryside, Syria. The durations of development of egg, $1^{\text {st }}$ and2 $2^{\text {nd }}$ larval instars, pupa, and adult at the three tested constant temperatures were measured. The total developmental period from egg to adult's emergence was estimated by 23.2, 13.3 and 10.8 days, respectively. The developmental period decreased significantly with increasing the temperature from 20 to $30^{\circ} \mathrm{C}$. Survival rate was the highest at temperature $\left(30^{\circ} \mathrm{C}\right)$ in comparison with the other temperatures $\left(20\right.$ and $25^{\circ} \mathrm{C}$ ). Egg stage of $\mathrm{S}$. sexmaculatus showed highest mortality levels at all temperatures. Generation period, as well as the ovipositional period decreased significantly at the temperatures ranged from 25.1 to 11.54 days, 52.8 to 41.2 days between the two temperature extremes, respectively. The maximum total fecundity (229.3 eggs/ female) and the minimum (94.1 eggs/female) were recorded at 30 and $20^{\circ} \mathrm{C}$, respectively. The mean number of fertile eggs, laid per female per day, was highest at $30{ }^{\circ} \mathrm{C}\left(4.9\right.$ eggs) and lowest $\left(2.7\right.$ eggs) at $20^{\circ} \mathrm{C}$. Thermal requirements for developmental thresholds and thermal constant of $S$. sexmaculatus were estimated as $10.8^{\circ} \mathrm{C}$ and 200 degree-days (DD), using the common linear model. $30^{\circ} \mathrm{C}$ was the optimum temperature for development. The results showed that the population of $S$. sexmaculatus was able to develop at a broad range of temperatures; therefore it is well adapted to the temperatures of the Mediterranean region.
\end{abstract}

Key words: Scolothrips sexmaculatus, Tetranychus urticae, Temperature-dependent, Thermal requirements, Biological parameters.

\section{INTRODUCTION}

The two spotted spider mite, Tetranychus urticae Koch. is an important, highly polyphagous and worldwide distributed pest of more than 900 host species include various species of orchard trees, field crops, ornamental plants and greenhouse plants (Modarres et al., 2011). It induces serious damage by direct feeding (Duso et al., 2008), reducing photosynthetic activity and leaf abscission in severe infestation (Alzoubi and Cobanoglu, 2008) who described this pest as a serious pest of at least 150 economically important plants. Chemical control of $T$. urticae in agronomic cropping systems often relies on foliar applications of several chemical classes of acaricides (Cranham and Helle, 1985). Several species of predatory thrips of the genus Scolothrips (Thysanoptera: Thripidae), especially the six-spotted thrips Scolothrips sexmaculatus, have been investigated for their potential to control spider mites, (Coville and Allen, 1977 and Gilstrap and Oatman, 1976). S. sexmaculatus is common in bean, cucumber and eggplant fields and has 
been demonstrated to be an important predator of several spider mite species, with a seasonal abundance correlated with that of the pest (Coville and Allen, 1977).

Temperature is an important abiotic factor that regulates physiological systems of insects and mites (Huffaker et al., 1999; Roy et al., 2002). In biological control, estimation of the developmental rates, longevity, survivorship, fecundity and temperatures of target pests and their natural enemies is important to understand their population dynamics and to develop sound pest management plans (Huffaker et al., 1999; Roy et al., 2002). Studies on the development of predators are needed for the prediction of their population phenology and dynamics in field and greenhouse crops. In addition, this knowledge reduces the discrepancies between field and laboratory observations and permitting the formulation of more reliable phenological models.

The aim of this study was to develop knowledge of the temperature-dependent development of the predator $S$. sexmaculatus stages, as a prerequisite for developing a prediction strategy under natural conditions.

\section{MATERIALS AND METHODS}

Laboratory studies were conducted at the General Commission for Scientific Agricultural Research (GCSAR), Damascus countryside, Syria, 2014.

\section{Mite culture}

A colony of the two-spotted spider mite ( $T$. urticae) was initiated using individuals originally collected from bean (Phaseolus vulgaris L. cv. Tema) fields in the Damascus countryside, Syria. A mass culture of the mite was maintained on potted bean plants at $25 \pm 1{ }^{\circ} \mathrm{C}, 60 \pm 10 \%$ $\mathrm{RH}$ and a photoperiod of $16 \mathrm{~L}: 8 \mathrm{D}$ hours for more than one year.

\section{Predator culture}

S. sexmaculatus individuals, found associated with $T$. urticae, were also collected from bean plants at the same location and transferred to the laboratory. The predatory species was identified, with the aid of a binocular microscope. Predator's culture was maintained for six months before been used in experiments (Parvin et al., 2010).

\section{Experimental Design}

The experiments were carried out in the laboratory at three constant $\left( \pm 1^{\circ} \mathrm{C}\right)$ temperatures $\left(20,25\right.$ and $\left.30^{\circ} \mathrm{C}\right), 60 \pm 10 \%$ $\mathrm{RH}$ and a photoperiod of 16L: 8D hours. The temperatures were chosen to cover a range suitable for development and survival of the predator. Bean plants, free of pesticides, were grown under laboratory conditions, leaf discs $(30 \mathrm{~mm}$ in diameter), without major veins, were cut and served as tested arena, according to the modified leaf-island method (Sengonca and Gerlach, 1983). Each disc was placed upside down on a layer of wet cotton inside Petri dishes $(60 \mathrm{~mm}$ in diameter). Lids of the Petri dishes had holes (15 $\mathrm{mm}$ in diameter) and covered with fine nylon mesh to allow ventilation. Each Petri dish was sealed with parafilm to prevent escape of the insects. To obtain prey eggs, 50 female mites from its colony were introduced onto clean bean leaves, kept in Petri dishes $(180 \mathrm{~mm}$ in diameter) and allowed to lay eggs (approximately 500 eggs) for $48 \mathrm{hs}$ in a climate cabinet at $26 \pm 1{ }^{\circ} \mathrm{C}, 60 \pm 10 \% \mathrm{RH}$, after which the female mites were removed. One-day-old adult thrips were transferred on to the bean leaves with $T$. urticae eggs every 2 days. The females laid their eggs singly in an incision made in the leaf disc with their ovipositor. The eggs were identified as whitish ellipses floating on a greenish background when viewed using transmitted light under a stereomicroscope. 
An experiment was carried out in order to standardize the age of the eggs of $S$. sexmaculatusin the laboratory $\left(26 \pm 1^{\circ} \mathrm{C}\right.$, $60 \pm 10 \% \quad \mathrm{RH}$ and a photoperiod of 16Lhrs.) by using 30 leaf discs, each was prepared by placing 20 female mites with one female thrips, taken from the stock with three 7-10-day-old male thrips, then the male thrips were removed after 12-24 $\mathrm{hr}$ from female eclosion.

Sixty one-day-old eggs of $S$. sexmaculatus were kept in a growth chamber at each temperature, so each treatment had 60 replications. Newly hatched $1^{\text {st }}$ instar larvae were transferred individually to fresh leaf discs. Larvae were fed daily by a surplus of different stages of T. urticae (about 100 preys were offered daily for each larva; the number of offered preys was higher than the consumption capacity). Immature individuals were transferred to fresh leaf discs every 2 or 3 day until emergence of the last adult predatory thrips. Developmental rate of immature individuals at each treatment was determined by inspecting the Petri dishes once daily and recording the developmental stage. Larval instars were determined based on larval size and the presence of larval exuviae.

Number of eggs laid was recorded daily until female thrips died and its longevity was determined. Sex ratio was established by incubating, hatching and rearing the progeny to adults. Unhatched eggs were also counted. The experiment continued till the last thrips died. Carey's method (Carey, 1993) was used to construct experimental life table parameters of $S$. sexmaculatus. The parameters of life table were constructed including the pivotal age for the age class in units of time (X), number of surviving individuals at the beginning of each age class (lx), number of alive individuals between age $x$ and $x+1$ (x.Lx), total number of individual $x$ age units beyond the age $\mathrm{x}$ (Tx) and the number of individuals dying during the age interval $\mathrm{x}(\mathrm{dx})$.

\section{Correlation between temperature and developmental rate}

The relationship between temperature and developmental rate was determined using the Sharp and DeMichele mathematic model and common linear model. The common linear model (Campbell et al., 1974) has been widely used for calculating the lower temperature thresholds and thermal constants (Roy et $a l .$, 2002). Moreover, it is the simplest method for estimation of the thermal constant (Walgama and Zalucki, 2006). The estimation of temperature thresholds and thermal constant for development of natural enemies can substantially contribute to the selection of the most suitable natural enemy to be used at different environmental conditions (Perdikis and Lykouressis, 2002). Low temperature threshold and thermal constant (K) needed to complete development from egg to adult, were calculated both by the common linear model. The first equation is:

$$
D_{r}=a+b T(1)
$$

Where:

$T$ is the temperature $\left({ }^{\circ} \mathrm{C}\right), D_{r}$ is the developmental rate (days), a is the intercept and $b$ is the slope. The lower temperature threshold $\left(\mathrm{T}_{0}\right)$ and the thermal constant ( $\mathrm{K}$, degree-days) were estimated using the parameters:

$\mathrm{T}_{0}=-\mathrm{a} / \mathrm{b}$ and $\mathrm{K}=1 / \mathrm{b}$

(Campbell, 1974).

\section{Satatiscal Anaysis}

One-way analysis of variance (ANOVA) was used to estimate significant differences in developmental period of $S$. sexmaculatus among the different temperatures. Means were separated by 
using the LSD Multiple range test at level $\mathrm{P}=0.01$.

\section{RESULTS AND DISCUSSION}

\section{Developmental period}

Total developmental period of $S$. sexmaculatus, from egg to adult emergence, was estimated by $23.2,13.3$ and 10.8 days, respectively. This agreed with Gotoh et al. (2004) for S. takahashii under similar dietary conditions (13.1 days), but compared with the results of Gilstrap and Oatman (1976), the developmental period of $S$. sexmaculatus at $25^{\circ} \mathrm{C}$ was shorter (16.1 days) when the predator was fed on Tetranychus pacificus McGregor on strawberry and (15.7 days) when fed on T. urticae on strawberry (Coville and Allen, 1977). Statistical analysis showed that the developmental period decreased significantly with increasing the temperature from 20 to $30^{\circ} \mathrm{C}$ (Table 1).

\section{Temperature threshold}

S. sexmaculatus lower temperature threshold for the entire developmental period and the thermal constant for females ,using the common linear model, were estimated by $10.8^{\circ} \mathrm{C}$ and 200 degree-days (DD), compared with $10{ }^{\circ} \mathrm{C}$ for S. longicornis (Pakyari, 2011) (Table $2)$. It was lower than the previously reported values of lower temperature thresholds estimated by linear models for S. takahashii $13.3^{\circ} \mathrm{C}$ (Gotoh et al., 2004 and Yamasaki, 1983), and for $S$. sexmaculatus $13.5^{\circ} \mathrm{C}$ (Coville and Allen, 1977 ; Gilstrap and Oatman, 1976).

\section{Influence of temperature on the development of $S$. sexmaculatus}

Developmental rate of $S$. sexmaculatus had influenced by the temperature and maybe other factors, such as nutrition, humidity, photoperiod and insecticide which were not included in the model presented here. Additionally, varying temperatures may exert different effects on the development of $S$. sexmaculatus than to constant temperatures (Zamani, 2007).

Longevities and duration of reproductive periods of the predator females, at the three constant temperatures, are shown in tables (3 and4). Reproductive parameters were compared, at the three temperatures $\left(20,25\right.$, and $\left.30^{\circ} \mathrm{C}\right), 60 \pm 10 \%$ relative humidity and a photoperiod of 16:8 h (light: dark). Highest rate of gross fecundity (GFR)(229.3 eggs/female)was recorded at $30^{\circ} \mathrm{C}$, compared with $(113.7$ eggs/female) for $S$. longicornis at similar conditions and at $26^{\circ} \mathrm{C}$ (67.8 eggs) for $S$. longicornis reported by (Pakyari and Enkegaard, 2012) which was less than that reported at similar temperatures at $25^{\circ} \mathrm{C}$ for $S$. longicornis (285.2 eggs /female) (Sengonca and Weigand,1988), S. takahashii (90.5 eggs /female (Gotohet al., 2004)) and S. sexmaculatus (153.8 eggs /female) (Covill and Allen, 1977)) and was greater than that reported for $S$. longicornis (48.9 eggs /female) at $25^{\circ} \mathrm{C}$ (Geibi and Hesami, 2011)). Even that expressed as daily fecundity, a difference was apparent for $S$. sexmaculatus between the present study (4.9 eggs/ female/ day) and S. longicornis (3.31eggs /female/day) (Pakyari and Enkegaard, 2012) and that of Sengonca and Weigand (1988) (6.3 eggs /female/day). The findings of Sengonca and Weigand (1988), for S.longicornis, when fed on TetranychuscinnabarinusBoisd.on cotton at $26^{\circ} \mathrm{C}$ differed than the present results, not only in terms of GFR and daily fecundity but also in terms of female longevity and ovipositional period as reported by Pakyari (2011). These noticeable differences might be related to differences in host plant and/or the prey used in the two studies and perhaps it indicates that cotton or $T$. cinnabarinuswas superior to $S$. 
longicornis compared with the cucumber-bean. Gross fertility rate was highest at $30^{\circ} \mathrm{C}(219.2 \mathrm{eggs} /$ female $)$ compared with (98.9 eggs /female) (Pakyari and Enkegaard, 2012) and lowest at $20^{\circ} \mathrm{C}$ (77.4 eggs/female). Daily number of eggs per female ranged from 2.7 to 4.9 eggs, with a minimum at $20^{\circ} \mathrm{C}$ and a maximum at $30^{\circ} \mathrm{C}$. This observation disagreed with (Pakyari and Enkegaard, 2012) who recorded that the mean of daily number of eggs per female ranged from 0.8 to 3.93 eggs and with a minimum at $15 \circ \mathrm{C}$ and a maximum at $35^{\circ} \mathrm{C}$. Obtained results demonstrated that $30^{\circ} \mathrm{C}$ was the optimum temperature for reproduction of $S$. sexmaculatus, adult females and males lived an average of 61.5 and 24.9 days, respectively, generation period was 11.54 days, and mated females continued laying eggs for 41.2 days, with an average of 0.75 days for the preovipositional period. Highest sex ratio for females $(80 \%)$ was recorded at $30^{\circ} \mathrm{C}$.

Means in each row with the same capital letter are not significantly different (using ANOVA test at $\mathrm{p}=0.01$ )

Age-specific survival rate is shown in table (5). Egg and larval mortality varied between 13.3 and $6.67,8.33$ and $1.67 \%$, at 20 and $30^{\circ} \mathrm{C}$, respectively. Agespecific survival rates of the immature stages of the $S$. sexmaculatus were.78.36, 88.3 and $90 \%$, respectively. Sex-ratio was in favor of females at all the tested temperatures and remained uninfluenced by temperatures at the range of $20-30^{\circ} \mathrm{C}$, with ratio values (females/females + males) of $0.74,0.74$ and 0.80 at 20,25 and $30^{\circ} \mathrm{C}$, respectively. Therefore, about $75 \%$ of the progeny were females.

\section{CONCLUSION}

The development rate of $S$. sexmaculatus may be influenced by factors other than temperature, such as nutrition, humidity, photoperiod and insecticide which were not included in the models presented here. Additionally, varying temperatures may exert different effects than do constant temperatures on the development of the predator.

The results have demonstrated that $S$. sexmaculatus population was able to develop and adapted to a broad range of temperatures that occur in the Mediterranean region. Additional studies should be conducted to study effect of crop varieties, prey stage and other environmental factors on the developmental rate of $S$. sexmaculatus.

\section{ACKNOWLEDGEMENTS}

The authors would like to thank the members of scientific committee of the symposium for reviewed the research. This research was financed by the General commission for scientific agriculture research (GCSAR), Syria.

\section{REFERENCES}

Alzoubi, S. and Cobanoglu, S. 2008. Toxicity of some pesticides against Tetranychus urticae and its predatory mites under laboratory conditions. American Eurasian Journal of Agricultural and Environmental Science, 3(1): 30-37.

Campbell, A., Frazer, B.D., Gilbert, N., Gutierrez, A.P and Mackauer, M. 1974. Temperature requirements of some aphids and their parasites. Journal of Applied Ecology, 11: 431438.

Carey, J.R. 1993. Applied demography for biologists with special emphasis on insects. New York (NY): Oxford University Press., 211 pp.

Coville, P.L. and Allen, W.W. 1977. Life table and feeding habits of Scolothrips sexmaculatus

(Thysanoptera:Thripidae).Annals of 
the Entomological Society of America, 70: 11-16.

Cranham, J.E. and Helle, W. 1985. Pesticide resistance in Tetranychidae, in World Crop Pests - Spider Mite: Their Natural Enemies and Control, Elsevier, Amsterdam, pp. 405-421.

Duso, C., Malagnini, V., Pozzebon, A. Castagnoli, M., Ligouri, M. and Simoni, S. 2008. Comparative toxicity of botanical and reduced-risk insecticides to Mediterranean populations of Tetranychus urticae and Phytoseiulus persimilis (Acari,Tetranychidae, Phytoseiidae). Biological Control, 47: 16-21.

Gheibi, M. and Hesami, S.H. 2011. Life table and reproductive table parameters of Scolothrips longicornis (Thysanoptera:Thripidae) as a predator of two-spotted spider mite, Tetranychus turkestani (Acari: Tetranychidae). World Academy of Science, Engineering and Technology 60:262-264.

Gilstrap, F.E. and Oatman, E.R. 1976. The bionomics of Scolothrips sexmaculatus (Pergande) (Thysanoptera: Thripidae), an insect predator of spider mites. Hilgardia, 44: 27-59.

Gotoh, T., Yamaguchi, K., Makiko, F. and Mori, K. 2004. Effect of temperature on life history traits of the predatory thrips, Scolothrips takahashii Priesner (Thysanoptera: Thripidae). Applied Entomology and Zoology, 39(3): 511-519.

Huffaker, C.B., Berryman, A. and Turchin, P. 1999. Dynamics and regulation of insect populations, In Huffaker, C.B. and Gutierrez, A.P. (ads.), Ecological Entomology, 2nd ed. Wiley, New York, 269-305.

Modarres N., Vafaei, S., Zamani, A.A. Arbabi, M. and Farazmand, H. 2011. Effect of nitrogen fertilization on Tetranychus urticae Koch. (Acari: Tetranychidae) populations on common bean cultivars. Middle-East
Journal Scientific Research, 8(5): 990998.

Pakyari, H. 2011. Development rate of Scolothrips longicornis (Thysanoptera:Thripidae) at various temperatures. Academic Journal of Entomology, 4 (1): 01-06.

Pakyari, H. and Enkegaard, A. 2012. Effect of different temperatures on reproductive performance of Scolothrips longicornis reared on Tetranychus urticae eggs. International Journal of Acarology, IFirst: 1-5,

Parvin, M.M., Asgar, M.A. and Haque, M.M. 2010. Voracity of three predators on two-spotted spider mite, Tetranychus urticae (Koch) (Acari: Tetranychidae) and their development stages. Research Journal of Agriculture and Biological Sciences, 6(1): 77-83.

Perdikis, D.C. and Lykouressis, D.P. 2002. Thermal requirements for development of the polyphagous predator Macrolophus pygmaeus (Hemiptera:Miridae). Environmental Entomology, 31: 661-667.

Roy, M., Brodeur, J. and Cloutier, C. 2002. Relationship between temperature and development rate of Stethorus punctillum (Coleoptera:Coccinellidae) and its prey Tetranichus mcdanieli (Acari:Tetranychidae). Environmental Entomology, 31(1): 177-187.

Sengonca, C. and Gerlach, S. 1983. A new developed method "leaf-island" for observation on thrips in the laboratory. Turk. Bit. Kor. Dery, 7: 1722.

Sengonca, C. and Weigand, S. 1988. Biology of predatory thrips, Scolothrips longicornis Priesner (Thysanoptera:Thripidae). Acta Phytopathologica et Entomologica Hungarica, 23(3-4):343-349.

Wagner, T.L., Wu, H., Sharpe, P.J.H. Schoolfield, R.M. and Coulson, R.N. 1984. Modeling insect development 
rates: a literature review and application of a biophysical model. Annals of the Entomological Society of America, 77: 208-225.

Walgama, R.S. and Zalucki, M.P. 2006. Evaluation of different models to describe egg and pupal development of Xyleborus fornicates Eichh. (Coleoptera: Scolytidae), the shot-hole borer of tea in Sri Lanka. Insect Science, 13: 109-118.

Yamasaki, Y., Yoshioka, K. and Takeuchi, F. 1983. Bionomics and predation of Scolothrips sp. Proceedings in Association of Plant Protection Shikoku, 18: 83-86. (In Japanese).

Zamani, A.A., Talebi, A.A., Fathipour, Y. and Baniameri, V. 2007. Effect of temperature on life history of Aphidius colemani and Aphidius matricariae (Hymenoptera:Braconidae) parasitoids of Aphis gossypii and Myzus persicae (Homoptera:Aphididae)

Environmental Entomology, 36: 263271. 